\title{
Research progress in recovering phosphorus from wastewater by crystallisation
}

\author{
Zhichao Yin ${ }^{1}$, Ying Fu ${ }^{1, *}$, Qingfeng Chen ${ }^{2, *}$ \\ ${ }^{1}$ School of Civil Engineering and Architecture, University of Jinan, Jinan 250022, China \\ ${ }^{2}$ Qilu University of Technology (Shandong Academy of Sciences), Jinan, 250014, China
}

\begin{abstract}
Phosphorus removal by crystallisation has the advantages of fast reactions, high efficiency, and recyclable resources, and it has attracted much attention at globally in recent years. With extensive research, its theory and process technology have been continuously improved. Magnesium ammonium phosphate (MAP) crystallisation and calcium hydroxyphosphate (hydroxyapatite, HAP) crystallisation are two common methods for wastewater dephosphorisation, but there are few reviews of these two methods. In this paper, the research results concerning MAP and HAP crystallisation methods are comprehensively reviewed. The reaction principle, influencing factors, and engineering applications of the two products are summarised, and the two crystallisation methods are compared. Finally, the development of future phosphorus crystallisation technology is discussed. These prospects provide a basis for the promotion and application of phosphorus removal by crystallisation.
\end{abstract}

\section{Introduction}

As a non-renewable resource, the reserves of phosphate rock on earth are limited. According to data released by the US Geological Survey in 2017, the total amount of phosphate ore resources is about 300 billion tonnes, which can meet the needs of the next 300 years based on the current consumption rate ${ }^{[1]}$. However, some scholars estimate that global phosphate ore resources will be exhausted within 100-250 years ${ }^{[2]}$. As a large country consuming phosphate resources, China had a total phosphate resource reserve of 18.63 billion tonnes at the end of 2010, which could be exploited for about 35 years. Simultaneously, a large amount of wastewater containing phosphorus was discharged into surface water, causing eutrophication of the water body and serious water pollution. Therefore, research on wastewater phosphorus removal and recycling technology has become a hot environmental issue ${ }^{[3]}$.

Crystallisation is a new method of wastewater dephosphorisation developed in recent years, which has the advantages of fast reactions, high efficiency, and recyclable resources. At present, phosphorus in wastewater is mainly removed by chemical precipitation and biological methods. However, these two methods make the phosphorus difficult to recycle. Phosphorus removal by crystallisation involves deposition of crystal phosphate in wastewater by controlling certain reaction conditions, and it can be used in recycling phosphorus, so it has broad research and application prospects ${ }^{[4]}$. Magnesium ammonium phosphate (MAP) crystallisation and calcium hydroxyphosphate (hydroxyapatite, HAP) crystallisation are two commonly used methods. In this paper, the principles, influencing factors, and practical engineering applications of these two crystallisation methods are summarised.

\section{MAP crystallisation}

\subsection{Principle of phosphorus removal by MAP crystallisation}

MAP, molecular formula $\mathrm{Mg}\left(\mathrm{NH}_{4}\right) \mathrm{PO}_{4} \cdot 6 \mathrm{H}_{2} \mathrm{O}$, is orthorhombic, commonly known as struvite, exists as white particles or powder, and is hardly soluble in water at room temperature; its main reactions are:

$$
\begin{aligned}
& \mathrm{Mg}^{2+}+\mathrm{NH}_{4}^{+}+\mathrm{PO}_{4}^{3-}+6 \mathrm{H}_{2} \mathrm{O} \rightarrow \mathrm{MgNH}_{4} \mathrm{PO}_{4} \cdot 6 \mathrm{H}_{2} \mathrm{O} \downarrow \\
& (1) \\
& \mathrm{Mg}^{2+}+\mathrm{NH}_{4}^{+}+\mathrm{HPO}_{4}^{2-}+6 \mathrm{H}_{2} \mathrm{O} \rightarrow \mathrm{MgNH}_{4} \mathrm{PO}_{4} \cdot 6 \mathrm{H}_{2} \mathrm{O} \downarrow \\
& +\mathrm{H}^{+}
\end{aligned}
$$

$$
\mathrm{Mg}^{2+}+\mathrm{NH}_{4}^{+}+\mathrm{H}_{2} \mathrm{PO}_{4}^{1-}+6 \mathrm{H}_{2} \mathrm{O} \rightarrow \mathrm{MgNH}_{4} \mathrm{PO}_{4} \cdot 6 \mathrm{H}_{2} \mathrm{O} \downarrow
$$$$
+2 \mathrm{H}^{+}
$$

(3)

Crystallisation occurs in solution when a reactant reaches a supersaturated state. Whether a compound can crystallise under certain conditions is usually determined by the saturation index (SI), which is calculated using equation (4) ${ }^{[5]}$ :

$$
S I=\log \frac{I A P}{K_{s p}}
$$




$$
I A P=\alpha\left(\mathrm{Mg}^{2+}\right) \cdot \alpha\left(\mathrm{NH}_{4}^{+}\right) \cdot \alpha\left(\mathrm{PO}_{4}^{3-}\right)
$$

Here, IAP is the ion activity product, $K_{s p}$ is the solubility product constant, and $\alpha\left(\mathrm{Mg}^{2+}\right), \quad \alpha\left(\mathrm{NH}_{4}^{+}\right), \quad \alpha\left(\mathrm{PO}_{4}^{3-}\right)$ are the corresponding ion activities. When the ion activity product is equal to the solubility product constant $(\mathrm{SI}=0)$, the solution is in equilibrium. When the ion activity product is less than the solubility product constant ( $\mathrm{SI}<0$ ), the solution is in an unsaturated state and no precipitation occurs. When the product is larger than the solubility product constant (SI > 0 ), the solution is in a supersaturated state and precipitation occurs. The ion activity product is increased so that the solution is supersaturated, MAP crystals are generated.

\subsection{Factors affecting MAP crystallisation}

MAP crystallisation is a hot research topic in current phosphorus recovery, and many experts have conducted extensive research on its influencing factors. The main factors affecting MAP formation include $\mathrm{pH}$, material molar ratio, seed crystal selection, and impurity effects. The following sections describe the research on these influencing factors.

\subsection{1 $\mathrm{pH}$}

Regarding the study of the factors affecting MAP, the first control factor to be determined is the $\mathrm{pH}$, which is an important factor in MAP crystallisation. Most of the $\mathrm{pH}$ ranges described in the literature tend to be alkaline ${ }^{[6-8]}$, and the optimum $\mathrm{pH}$ is about $8 \sim 9$. When $\mathrm{pH}<7, \mathrm{PO}_{4}{ }^{3-}$ exists as $\mathrm{H}_{2} \mathrm{PO}_{4}^{-}$, which is not conducive to MAP crystallisation. However, as the solution $\mathrm{pH}$ increases, the efficiency of MAP crystallisation decreases and the solubility increases. Song et al. ${ }^{[9]}$ believe that there are two main reasons for this: first, if the $\mathrm{pH}$ is too high, the hydroxide in the solution increases, the phosphate competes with $\mathrm{Mg}^{2+}$, and $\mathrm{OH}^{-}$and $\mathrm{Mg}^{2+}$ form $\mathrm{Mg}(\mathrm{OH})_{2}$ precipitate, which affects MAP crystallisation. This is because at high $\mathrm{pH}$, a large amount of $\mathrm{NH}_{4}{ }^{+}$is converted to $\mathrm{NH}_{3}$, which also reduces supersaturation. However, a study by Hao ${ }^{[10]}$ and other quantitative analyses of precipitates obtained under different $\mathrm{pH}$ conditions using elemental analysis showed that the optimal formation conditions for pure MAP crystals are neutral, rather than alkaline with high $\mathrm{pH}$. Therefore, the optimum solution $\mathrm{pH}$ range for obtaining relatively pure MAP is 7 9.

\subsubsection{Substance molar ratio}

It can be clearly seen from equation (1) that the molar ratio $\mathrm{NH}_{4}{ }^{+}: \mathrm{Mg}^{2+}: \mathrm{PO}_{4}{ }^{3-}$ is $1: 1: 1$. However, the $\mathrm{Mg}^{2+}$ dosage can be appropriately increased to increase the phosphate recovery rate. This is related to the influence of impurities in the actual wastewater. The wastewater contains more $\mathrm{CO}_{3}{ }^{2-}$ and other impurity ions that co-precipitate with $\mathrm{Mg}^{2+}$, which reduces the $\mathrm{Mg}^{2+}$ concentration involved in the MAP reaction. Therefore, it is necessary to add excess magnesium source. He et al. ${ }^{[1]}$ used a large amount of magnesium salt in seawater to study the removal of nitrogen and phosphorus from wastewater, and the optimum ratio was $\mathrm{Mg}: \mathrm{N}: \mathrm{P}=1.3: 1: 0.8(\mathrm{Mg}: \mathrm{P}=1.6)$. Shang et al. ${ }^{[12]}$ studied phosphorus recovery from landfill leachate, where the optimum ratio was $\mathrm{Mg}: \mathrm{N}: \mathrm{P}=1: 1: 0.7$ $(\mathrm{Mg}: \mathrm{P}=1.4)$. Chang et al. ${ }^{[13]}$ discussed the recovery of phosphorus in the form of struvite from the anaerobic fermentation supernatant of residual sludge, and the best ratio was $\mathrm{Mg}: \mathrm{P}=1.6 \sim 1.8$. Therefore, to maximise phosphorus recovery, the molar ratio of magnesium to phosphorus should be controlled between 1.4 and 1.8 .

\subsubsection{Type of seed crystal}

In MAP crystallisation, the use of seed crystals positively affects crystal growth. Introducing seed crystals can reduce the activation energy required for MAP crystallisation and shorten the nucleation time ${ }^{[14]}$. However, introducing seed crystals can increase the volume of crystals, facilitate their separation from water, and improve the efficiency and recovery of phosphorus removal. There are many types of seed crystals, mainly pumice, microsand, mother crystal (MAP itself acts as a seed crystal), steel slag, slag, and stainless steel ${ }^{[15-18]}$.

Bishop et al. ${ }^{[16]}$ experimented with microsand and MAP as seed crystals; both materials increased the reaction rate and MAP seeds were superior to microsand seeds. Ma ${ }^{[17]}$ used steel slag, slag, and quartz sand as seed crystals. Steel slag seed crystals showed the highest phosphorus removal rate, followed by slag, while quartz sand was the worst. Corre et al. ${ }^{[18]}$ used stainless steel mesh as a seed crystal, which not only promoted the deposition of MAP crystals but also captured those formed in the solution. After reacting for $2 \mathrm{~h}$, the phosphorus removal efficiency reached $81 \%$. Laridi et al. [19] added preformed MAP crystals, achieving a phosphorus recovery rate of $98 \%$. Therefore, pre-seeding can accelerate the crystal growth rate and shorten the crystallisation time. Simultaneously, the surface of the seed crystal should contain MAP-like components. Such a seed crystal will have a better phosphorus removal effect, so the mother crystal can be used as a seed crystal to obtain a higher phosphorus recovery rate.

\subsubsection{Water impurities}

Wastewater usually contains various impurities, including anions and cations such as $\mathrm{Cu}^{2+}, \mathrm{Zn}^{2+}$, and $\mathrm{CO}_{3}{ }^{2-}$, suspended solids (SS), and organic substances, and the presence of impurities has an interference effect on MAP crystals. Muryanto et al. ${ }^{[20]}$ studied the effects of common metal ions $\mathrm{Cu}^{2+}$ and $\mathrm{Zn}^{2+}$ on MAP crystallisation in aquaculture wastewater. The nucleation time and growth rate of MAP was affected by $\mathrm{Cu}^{2+}$ and $\mathrm{Zn}^{2+}$, although their effect on crystal shape was insignificant. However, they caused cracks on the crystal surfaces. Zhang et al. ${ }^{\text {[21] }}$ increased the $\mathrm{CO}_{3}{ }^{2-}$ concentration in a MAP crystallisation experiment with aquaculture wastewater and increased the molar ratio of $\mathrm{CO}_{3}{ }^{2-}$ to $\mathrm{NH}_{4}{ }^{+}$. Excess $\mathrm{CO}_{3}{ }^{2-}$ and $\mathrm{Mg}^{2+}$ reacted to form $\mathrm{MgCO}_{3}$ precipitate, which in turn reduced the $\mathrm{Mg}^{2+}$ concentration. Regarding 
the formation of MAP crystals. Li et al. ${ }^{[22]}$ found that at $\mathrm{pH} 8$, the suspended matter was negatively charged and combined with positively charged $\mathrm{NH}_{4}{ }^{+}$and $\mathrm{Mg}^{2+}$ in the water to affect the formation of MAP crystals. At $\mathrm{pH}$ 8.5 9, a high content of suspended matter may act as a seed crystal, promoting heterogeneous nucleation of MAP and affecting crystal purity. $\mathrm{Hu}$ et al. ${ }^{[23]}$ explored the effects of four typical compounds, organic sodium alginate, bovine serum albumin, humic acid, and glucose on MAP crystallisation. The results showed that the presence of small glucose molecules minimally affected MAP crystallisation. Large molecules can form complexes with $\mathrm{Mg}^{2+}$, which is not conducive to the formation of MAP crystals. Therefore, when recovering phosphorus from wastewater, suspended solids, macromolecular organic matter, and other interfering ions in the wastewater must be reduced by pretreatment.

\subsection{Application of MAP crystallisation method}

Crystallisation water treatment has evolved from academic theory to operational engineering practice ${ }^{[24]}$. While phosphorus removal by crystallisation has been applied to many practical projects abroad, domestic research remains limited to laboratory or pilot tests, and it is rarely used in practical engineering.

In sewage plants with high nitrogen and phosphorus concentrations in foreign countries, the existing biochemical treatment facilities combined with sewage treatment are supplemented with a bypass crystallisation and phosphorus removal process, which can improve the phosphorus recovery rate. Canada's Gold Bar Wastewater Treatment Plant used Ostar's phosphorus crystallisation technology in 2007 to recover more than $80 \%$ of phosphorus and about $15 \%$ of ammonia from wastewater, producing about $500 \mathrm{~kg}$ of MAP per day ${ }^{[25]}$. Japan's Ube Industries uses phosphorus crystallisation to recycle "Green MAP II", which is widely acclaimed in Japan as an environmentally friendly fertiliser ${ }^{[26]}$. Furthermore, Japan's Hiagari Sewage Treatment Plant uses seawater as a source of magnesium to treat sludge dewatering supernatants with a phosphorus recovery rate of $70 \%{ }^{[27]}$; Both Slough sewage treatment plant in the UK and Oxley Creek sewage treatment plant in Brisbane, Australia, use MAP crystallization method to recover more than $90 \%$ phosphorus in high-phosphorus wastewater ${ }^{[28-29]}$.

Although the domestic phosphorus crystallisation technology is late in developing, in recent years, with gradual improvement of the basic theory, some environmental protection companies have begun to use crystallisation to treat high-phosphorus wastewater. For example, Zhejiang Huahai Pharmaceutical Co., Ltd. discharged high-phosphorus wastewater with a total phosphorus content of about 40,000-50,000 mg/L during production and built several MAP crystallisation treatment facilities through an investment of 1.53 million yuan. The total phosphorus in the effluent was below 200 $\mathrm{mg} / \mathrm{L}$, and the total removal rate was $99.6 \%$, indicating stable operation ${ }^{[30]}$.

\section{HAP crystallisation}

\subsection{Principle of phosphorus removal by HAP crystallisation}

HAP is also known as calcium hydroxyphosphate or basic calcium phosphate.

HAP formation is represented by equation (6):

$$
5 \mathrm{Ca}^{2+}+3 \mathrm{PO}_{4}^{3-}+\mathrm{OH}^{-} \rightarrow \mathrm{Ca}_{5}\left(\mathrm{PO}_{4}\right)_{3} \mathrm{OH} \downarrow
$$

When $\mathrm{Ca}^{2+}, \mathrm{PO}_{4}{ }^{3-}$, and $\mathrm{OH}^{-}$in the solution reach supersaturation, the phosphate and calcium ions form a calcium phosphate precipitate, which is finally converted into HAP crystals. When the solution $\mathrm{pH}$ changes, the $\mathrm{Ca}^{2+}$ and $\mathrm{PO}_{4}{ }^{3-}$ contents differ, and different calcium phosphate phases are formed, such as amorphous calcium phosphate $\left(\mathrm{Ca}_{3}\left(\mathrm{PO}_{4}\right)_{2} \cdot \mathrm{nH}_{2} \mathrm{O}, \mathrm{ACP}\right)$, calcium phosphate $\left(\mathrm{Ca}_{3}\left(\mathrm{PO}_{4}\right)_{2}, \mathrm{TCP}\right)$, a precursor of HAP, calcium hydrogen phosphate $\left(\mathrm{CaHPO}_{4} \cdot 2 \mathrm{H}_{2} \mathrm{O}, \mathrm{TCPD}\right)$, and octacalcium phosphate $\left(\mathrm{Ca}_{4} \mathrm{H}\left(\mathrm{PO}_{4}\right)_{3} \cdot 2.5 \mathrm{H}_{2} \mathrm{O}\right.$, OCP $)$, but most of the precursor materials are thermodynamically stabilised by recrystallisation. Unlike MAP, which is formed directly, HAP requires recrystallisation of a precursor phase such as ACP, TCP, TCPD, or OCP.

\subsection{Factors influencing HAP crystallisation}

\subsection{1 $\mathrm{pH}$}

As with MAP, $\mathrm{pH}$ is an important factor influencing HAP crystallisation. When the $\mathrm{pH}$ is low, the ion activity product is smaller than the solubility product constant, the crystallisation rate is slow, and crystallisation does not occur readily; when the $\mathrm{pH}$ is too high, the $\mathrm{OH}^{-}$in the solution increases, and $\mathrm{OH}^{-}$and $\mathrm{PO}_{4}{ }^{3-}$ compete for $\mathrm{Ca}^{2+}$ in forming $\mathrm{Ca}(\mathrm{OH})_{2}$ precipitate, affecting the formation of HAP crystals. Gu et al. ${ }^{[31]}$ used bovine bone meal as seed crystals. With a Ca:P ratio of 1.67 and a reaction time of $2 \mathrm{~h}$, the effect of different $\mathrm{pH}$ values on HAP crystallisation was investigated. The results showed that the recovery rate of phosphorus increased with the $\mathrm{pH}$. At $\mathrm{pH} 10.5$, the recovery rate reached $91.7 \%$. However, when the $\mathrm{pH}$ increased from 10 to 10.5 , the recovery rate did not change significantly, so the optimum $\mathrm{pH}$ should be 10 . Guan et al. ${ }^{[32]}$ found that when the $\mathrm{pH}$ was below 7 , the removal rate of phosphorus was almost zero. When the $\mathrm{pH}$ exceeded 8 , the phosphorus concentration was reduced from $10 \mathrm{mg} / \mathrm{L}$ to below $5 \mathrm{mg} / \mathrm{L}$. When the $\mathrm{pH}$ exceeded 9, the effluent phosphorus concentration was reduced to below $1 \mathrm{mg} / \mathrm{L}$. Therefore, HAP is easily formed under alkaline conditions, and the optimum $\mathrm{pH}$ for producing HAP is 9 to 10 , which is slightly higher than that for the MAP crystallisation mentioned above.

\subsubsection{Substance molar ratio}

It can be seen from equation (6) that the $\mathrm{Ca}: \mathrm{P}$ ratio of the HAP crystals is theoretically $1.67: 1$. To increase the phosphorus recovery rate, the $\mathrm{Ca}^{2+}$ concentration should be appropriately increased, and the $\mathrm{Ca}: \mathrm{P}$ ratio should be increased to increase the supersaturation of the solution to 
promote crystallisation. Zou et al. ${ }^{[33]}$ found that when $\mathrm{Ca}: \mathrm{P}$ was below 1.67 (in the experiment, $\mathrm{Ca}: \mathrm{P}$ was 1.5 ), the phosphorus recovery rate was $68.5 \%$, and when When $\mathrm{Ca}: \mathrm{P}$ is less than 1.67 (in the experiment, $\mathrm{Ca}: \mathrm{P}$ is 1.5), the phosphorus recovery rate is $68.5 \%$. When $\mathrm{Ca}: \mathrm{P}$ increases from 1.5 to 2.5 , the phosphorus recovery rate can reach over $92 \%$. Duan ${ }^{[34]}$ studied the effect of different Ca:P ratios on HAP crystallisation with converter slag as the seed material. The results showed that the optimum $\mathrm{Ca}: \mathrm{P}$ $=2$, which is consistent with the conclusions of Gu Caixia ${ }^{[31]}$. Song et al. ${ }^{[35]}$ pointed out that increasing Ca:P can overcome the effect of carbonate ions on calcium phosphate. Increasing $\mathrm{Ca}: \mathrm{P}$ can increase the phosphorus removal rate, but $\mathrm{Ca}: \mathrm{P}$ should not exceed 5 . Therefore, to improve the supersaturation of the solution to promote HAP crystallisation, the optimum $\mathrm{Ca}: \mathrm{P}$ should be 2-2.5.

\subsubsection{Seed selection}

The presence of seed crystals during HAP crystallisation helps to reduce the activation energy required for crystallisation, increase the crystallisation rate, and shorten the nucleation process. To explore cheap seed crystals, scholars at home and abroad have conducted much research. Bellier et al. ${ }^{[36]}$ selected four types of phosphate ore as seed crystals to study their phosphorus recovery ability and found that HAP crystals could be formed in sedimentary rock ore. Other seed materials include bovine bone meal, coral sand, oyster shell, porous ceramsite, dolomite lime, and hard calcium stone ${ }^{[31,37-40]}$. These materials have a phosphorus removal rate exceeding $90 \%$. The seed crystals commonly found in HAP crystallisations contain phosphorus and calcium components. Because they have a similar lattice to HAP, they preferentially adsorb calcium and phosphorus ions from the solution, so that the local ion concentration exceeds the solubility product of HAP and crystals are rapidly deposited on their surfaces.

\subsubsection{Water impurities}

The wastewater has a complex content, with impurities such as $\mathrm{CO}_{3}{ }^{2-}$, metal ions, and various organic substances in addition to calcium and phosphorus ions constituting HAP crystals. These impurities react with the constituent ions, hinder the formation and conversion of HAP crystals, and affect the purity and morphology of the crystal product, which is not conducive to subsequent recycling of the product ${ }^{[41]}$.

$\mathrm{CO}_{3}{ }^{2-}$ is common in wastewater. A large amount of $\mathrm{CO}_{3}{ }^{2-}$ will form $\mathrm{CaCO}_{3}$ precipitate with $\mathrm{Ca}^{2+}$ or be doped in the HAP crystals, changing their morphology, structure, and composition. Zhao et al. ${ }^{[42]}$ studied the effect of $\mathrm{CO}_{3}{ }^{2-}$ on calcium phosphate crystallisation with different $\mathrm{Ca}: \mathrm{P}$ values. At $\mathrm{pH} 9, \mathrm{Ca}: \mathrm{P}$ was 1.67 , and $\mathrm{CO}_{3}{ }^{2-}$ could replace $\mathrm{PO}_{4}{ }^{3-}$ in the HAP structure to form carbon phosphate.; at $\mathrm{Ca} P \mathrm{P}$ values of 3.33 and $5.01, \mathrm{CO}_{3}{ }^{2-}$ forms $\mathrm{CaCO}_{3}$ precipitate with $\mathrm{Ca}^{2+}$.

When metal ion radii are close to that of $\mathrm{Ca}^{2+}$, substitution or competitive reactions are likely. Tan et al. ${ }^{[43]}$ studied the effect of $\mathrm{Zn}^{2+}$ on phosphorus removal using
HAP crystallisation. When the $\mathrm{pH}$ was low, $\mathrm{Zn}^{2+}$ replaced some $\mathrm{Ca}^{2+}$ and formed $\mathrm{Zn}_{3}\left(\mathrm{PO}_{4}\right)_{2}$ with $\mathrm{PO}_{4}{ }^{3-}$; when the $\mathrm{pH}$ was high, $\mathrm{Zn}^{2+}$ competed for HAP. $\mathrm{OH}^{-}$in the crystal formed a $\mathrm{Zn}(\mathrm{OH})_{2}$ precipitate.

Wastewater contains many types of organic matter, and some organic substances may affect the formation of HAP crystals. Ren et al. ${ }^{[4]}$ used phosphorus-containing wastewater containing humus (HS) as a research object. The results showed that HAP crystallisation could simultaneously remove phosphorus and HS, but the presence of HS reduced the efficiency of phosphorus removal. Song et al. ${ }^{[45]}$ also found that HS reduced the crystallisation rate of HAP, but increasing the solution $\mathrm{pH}$ (to above 9) could effectively reduce the effect of HS on HAP crystallisation. Song et al. ${ }^{[46]}$ found that acetic and succinic acids in solution minimally affected HAP crystallisation, while citric acid significantly affected the removal rate of phosphorus by HAP crystallisation, which may be due to the active sites of citric acid and calcium phosphate. Point combination increases the saturation of the crystallisation, inhibiting precipitation.

\subsection{Practical application of HAP crystallisation}

In the area of wastewater treatment and resource recycling, the Netherlands, as a pioneer in European water treatment, built two crystal dephosphorisation demonstration plants at Geestmerambacht and Heemstede for treating urban sewage in 1993. The inlet water concentration of the crystal reactor is about $80 \mathrm{mg} / \mathrm{L}$, the recovery rate of phosphorus can reach $70 \% \sim 80 \%$, and the recovered HAP crystals are utilised in the phosphate industry ${ }^{[47]}$. Also used in the Netherlands is a DHV crystallisation reactor, which uses quartz sand as seed crystals. The $\mathrm{pH}$ is adjusted by adding sodium hydroxide or lime milk. HAP crystals are deposited on the surface of quartz sand to form crystal particles containing $40 \%$ to $50 \%$ HAP and $30 \%$ to $40 \%$ seed material ${ }^{[48]}$.

\section{Comparison of the two crystallisation methods}

It is known from the equation for MAP crystallisation that the ammonia nitrogen concentration in wastewater is low $(\mathrm{N}: \mathrm{P}<1)$. It is not feasible to recover phosphorus by MAP crystallisation, because in addition to adding a magnesium source, a nitrogen source is added, while HAP crystallisation involves adding only a single calcium source. However, the optimum $\mathrm{pH}$ for HAP crystallisation is slightly higher than 9 compared with 9 for the formation of MAP crystals, which increases the amount of hydroxide added during crystallisation and increases the process cost. Simultaneously, to remove the same number of moles of phosphorus, the number of moles of calcium required for HAP is theoretically 1.67 times that of magnesium in MAP, increasing the dosage of the calcium source. Adding seed crystals to both crystallisations reduces the activation energy, shortens the nucleation time of the crystals, and accelerates the crystallisation. Therefore, a seed crystal that is cheap, easily obtained, 
and similar in composition to the parent crystal is selected. Increasing the reaction rate is important.

Wastewater compositions are complex, and the impurities affecting the two crystallisations are different. However, the $\mathrm{CO}_{3}{ }^{2-}$ concentration in both crystallisations should not be too high, as $\mathrm{CO}_{3}{ }^{2-}$ will compete for calcium and magnesium sources to form carbonate precipitates, affecting the crystal structure and formation. In terms of practical engineering applications, MAP is a highly effective slow-release fertiliser that can be used directly, widening its application. It is used in China and many other countries. HAP is the main component of phosphate rock. Further processing allows its use as a phosphate fertiliser, which may be the reason for its reduced use in engineering applications.

Table 1 shows an inductive comparison of the two crystallisation methods

Table 1. Comparison of MAP and HAP crystallisation methods

\begin{tabular}{|c|c|c|c|c|c|c|}
\hline & \multirow[b]{2}{*}{ Reaction equation } & \multicolumn{4}{|c|}{ Main influencing factor } & \multirow{2}{*}{$\begin{array}{c}\text { Practical } \\
\text { engineering } \\
\text { applications } \\
\end{array}$} \\
\hline & & $\begin{array}{c}\text { Optimum } \\
\text { pH }\end{array}$ & $\begin{array}{c}\text { molar } \\
\text { ratio }\end{array}$ & Seed selection & Impurity & \\
\hline MAP & $\begin{array}{l}\mathrm{Mg}^{2+}+\mathrm{NH}_{4}^{+}+\mathrm{PO}_{4}^{3-}+6 \mathrm{H}_{2} \mathrm{O} \rightarrow \\
\mathrm{MgNH}_{4} \mathrm{PO}_{4} \cdot 6 \mathrm{H}_{2} \mathrm{O} \downarrow\end{array}$ & $7 \sim 9$ & $\begin{array}{l}\mathrm{Mg}: \mathrm{P}= \\
1.4 \sim 1.8\end{array}$ & $\begin{array}{l}\text { Pumice, micros- } \\
\text { and, parent cryst- } \\
\text { al, steel slag, slag, } \\
\text { and stainless steel. }\end{array}$ & $\begin{array}{c}\mathrm{CO}_{3}{ }^{2-}, \\
\text { Metal ions }\left(\mathrm{Cu}^{2+} \text {, }\right. \\
\left.\mathrm{Zn}^{2+}\right) \\
\text { Organic matter } \\
\text { (sodium alginate, } \\
\text { bovine serum } \\
\text { albumin, humic } \\
\text { acid), and } \\
\text { suspended solids. }\end{array}$ & More \\
\hline HAP & $\begin{array}{l}3 \mathrm{PO}_{4}^{3-}+5 \mathrm{Ca}^{2+}+\mathrm{OH}^{-} \rightarrow \\
\mathrm{Ca}_{5}\left(\mathrm{PO}_{4}\right)_{3} \mathrm{OH} \downarrow\end{array}$ & $9 \sim 10$ & $\begin{array}{l}\text { Ca:P = } \\
2 \sim 2.5\end{array}$ & $\begin{array}{l}\text { Phosphate rock } \\
\text { ore, bovine bone } \\
\text { powder, coral } \\
\text { sand, oyster shell, } \\
\text { porous ceramsite, } \\
\text { dolomite lime, } \\
\text { hard calcium } \\
\text { stone. }\end{array}$ & $\begin{array}{c}\mathrm{CO}_{3}{ }^{2-} \\
\text { Metal ion }\left(\mathrm{Zn}^{2+}\right) \\
\text { Organic matter } \\
\text { (humus, citric acid). }\end{array}$ & Few \\
\hline
\end{tabular}

\section{Conclusions and prospects}

At present, China's phosphorus resource crisis is becoming increasingly severe. Large amounts of phosphorus resources are discharged into water bodies, causing eutrophication. Phosphorus crystallisation technology undoubtedly enables effective phosphorus recovery and utilisation. In summary, phosphorus removal by crystallisation is mainly affected by $\mathrm{pH}$, molar ratios, seed crystals, and water impurities. The water quality of different water bodies differs considerably. Based on the characteristics of wastewater, the requirements, and the use of precipitation products, an appropriate crystallisation method should be selected to achieve removal and recovery of phosphorus by controlling the conditions required for crystallisation.

Currently, crystallisation dephosphorisation technology is applied to a certain extent, but it involves large amounts of chemicals and a high operating cost. Therefore, research must be conducted in the following areas:

1) Crystalline products recovered from highly polluted wastewater may be contaminated with heavy metals or other toxic substances, which may migrate during use and cause serious problems in their application. Therefore, it is necessary to further evaluate the practicability and safety of crystallization products in highly polluted wastewater.
2) With respect to seeking suitable calcium and magnesium sources and seed crystals, the costs of different seed crystals and the effects of phosphorus removal differ. Therefore, developing a high efficiency, low-cost and material-based calcium and magnesium source is highly significant with regard to crystallisation development.

3) Developing a coupling process for phosphorus removal by crystallisation and other phosphorus removal methods is different from the separate construction of biological and chemical units in conventional water plants, which combines crystallisation and biological methods and attempt to use microorganisms to promote crystallisation. This may be a research hotspot in the future of wastewater phosphorus removal technology.

\section{References}

1. L. Zhang, H P. Yang, A S. Feng, et al. Conservation and Utilization of Mineral Resources, 05,105-112 (2017)

2. X D. Hao, L K. Yi, C C. Wang, et al. J ENVIRON SCI-CHINA, 30,3925-3940(2002)

3. J D. Doyle, S A. Parsons, WATER RES, 36, $3925-$ 3940(2002)

4. G W. Wang, L P. Qiu, S B. Zhang, Technology Of Water Treatment, 36,17-22(2010) 
5. G A. Momberg, R A. Oellermann, WATER SCI TECHNOL, 26,987-996(1992)

6. L. Pastor, D. Mangin, R. Barat, et al . BIORESOURCE TECHNOL, 99,6285-6291(2008)

7. K S L. Corre, E. Valsami-Jones, P. Hobbs, et al, J CRYST GROWTH, 283, 514-522,(2005)

8. N. Marti, A. Bouzas, A. Seco, et al. CHEM ENG J, 141,67-74(2008)

9. Y H. Song, P. Yuan, B H. Zheng, et al. CHEMOSPHERE， 69,319-324(2007)

10. X D. Hao, C C. Wang, L. Lan, et al. WATER SCI TECHNOL, 58,1687-1692(2008)

11. J. He, F F. Zhao, P J. Liu, et al. Environmental Science and Management, 36,73-75(2011)

12. A A. Shang, Q X. Zhao, M Y. Xu, et al. Water \& Wastewater Engineering, 30,22-25(2004)

13. X. Chang, W. Zeng, B G. Wang, et al. Environmental Science, 1-3(2019)

14. E H. Kim, S B. Yim, H C. Jun, et al. J HAZARD MATER, 136, 690-697(2006)

15. N B. Pakdil, A. Filibeli, J RESIDUALS SCI TECH, 5,95-102(2008)

16. Bishop, L. Paul, J ENVIRON ENG SCI, 3,2129(2004)

17. J. Ma, University of Jinan(2012)

18. K S. Corre, E. Jones, P. Hobbs, et al. WATER RES, 41,2449-2456(2007)

19. R. Laridi, J C. Auclair, H. Benmoussa, ENVIRON TECHNOL 26,525-536(2005)

20. S. Muryanto, A P. Bayuseno, POWDER TECHNOL, 253,602-607(2014)

21. T. Zhang, C. Fang, P. Li, et al. ENVIRON PROT ENG, 40,29-42(2014)

22. L. Li, D H. Wang, X. Zou, et al. Transactions of the Chinese Society of Agricultural Engineering, 26,265271(2010)

23. D X. Hu, Y. Zhang, Y. Luo, et al. China Water \& Wastewater, 34,1-6(2018)

24. K J. Wang, Y. Xiong, Z. Yan, Chinese Journal of Environmental Engineering, 4,1-7(2010)

25. Z G. Liu, Q L. Zhao, L L. Wei, et al. J CHEM TECHNOL BIOT, 86,1394-1398(2011)

26. Y. Ueno, M. Fujii, ENVIRON TECHNOL, 22,13731381(2001)

27. K. Kumashiro, H. Ishiwatari, Y. A. Nawamura, Second International Conference on the Recovery of Phosphorus from Sewage and Animal Wastes, (2001)

28. Y. Jaffer, T A. Clark, P. Pearce, et al. WATER RES, 36,1834-1842(2002)

29. E V. Münch, K. Barr, WATER RES, 35,151159(2001)

30. Z J. Wu, X. Song, M Z. Hu, et al. China Water \& Wastewater, 27, 54-46+60(2011)

31. C X. Gu, C J. Zhang, Y M. Li, et al. Chinese Journal of Environmental Engineering, 9,(2015)
32. W. Guan, F Y. Ji, Q K. Chen, et al. MATER RES INNOV, 18,43-49(2014)

33. H M. Zou, X W. Lv, T. Li, Journal of Southeast University, 43,1005-1010(2013)

34. J M. Duan, Y P. Zhang, H D. Fang, et al. Chinese Journal of Environmental Engineering, 4,15761580(2010)

35. Y. Song, H. Hahn, E. Hoffmann, ENVIRON TECHNOL, 23,207-215(2002)

36. N. Bellier, F. Chazarenc, Y. Comeau WATER RES, 40,2965-2971(2006)

37. R. Zhang. Beijing Municipa Research Institute of Environmental Protection(2012)

38. L S. Zhang, F. Lin, H S. Wu, et al. Southeast University, 664-667(2003)

39. J. Ge, F. Qian, Y H. Song, et al. J. Environ. Sci, 34,1480-1488(2014)

40. X. Chen, H. Kong, D. Wu, et al. J ENVIRON SCICHINA, 21,575-580(2009)

41. Z. Wang, B. Du, Y. liu, Environmental Engineering, 53,16-20(2015)

42. Y L. Zhao, Y H. Song, F. Qian, et al. Chinese Journal of Environmental Engineering, 8,1755-1760(2014)

43. J, Tan, L L. Ding, M Y. Zhao, et al. Environmental Science \& Technology, 33,54-58(2010)

44. W C. Ren, Z. Zhou, X Y. Huang, J ENVIRON SCICHINA, 35,3545-3551(2015)

45. Y H. Song , H. Hahn, E. Hoffmann, et al. J ENVIRON SCI-CHINA, 18,852-857(2006)

46. Y H. Song, Q. Hu, Y R. Dai, et al. J ENVIRON SCICHINA, 34,894-901(2014)

47. D H J A M. Van , E. Valsami-Jones, ENVIRON TECHNOL, 22,1325-1335(2001)

48. G K. Morse, S W. Brett, J N. Guy, et al. SCI TOTAL ENVIRON, 212,69-81(1998) 